\title{
Precariedade e interdisciplinaridade no trabalho da Assistente Social na esfera pública
}

\author{
Vicente de Paula Faleiros ${ }^{1}$ \\ https://orcid.org/0000-0002-9540-5355
}

\section{Helga Cristina Hedler ${ }^{2}$}

https://orcid.org/0000-0003-3895-5200

\author{
Adelina Almeida Moreira de Araújo ${ }^{3}$ \\ https://orcid.org/0000-0002-1160-3267
}

\footnotetext{
${ }^{1}$ Universidade de Brasília, Departamento de Serviço Social, Brasília, DF, Brasil

${ }^{2}$ Universidade Católica de Brasília, Programa de Pós-Graduação Stricto Sensu em Governança, Tecnologia e Inovação, Brasília, DF, Brasil

${ }^{3}$ Universidade Católica de Brasília, Departamento de Psicologia, Programa de Mestrado e Doutorado em Psicologia, Brasília, DF, Brasil
}

Precariedade e interdisciplinaridade no trabalho da Assistente Social na esfera pública

Resumo: Este artigo resulta de uma pesquisa com gestoras assistentes sociais nas esferas jurídicas, da assistência social e da saúde no Distrito Federal no contexto das políticas de proteção social. Objetivou-se analisar as percepções sociais dessas gestoras sobre a questão da precariedade e da interdisciplinaridade do trabalho de assistentes sociais em sua interação com psicólogos(as). A metodologia do estudo é qualitativa por meio de entrevistas semiestruturadas. Os resultados apontam para a precarização do trabalho social no contexto de neoliberalização, com consequências de sobrecarga e de estresse no cotidiano das profissionais.

Palavras-chave: Precarização do trabalho. Serviço Social na saúde. Serviço Social sociojurídico. Serviço Social e assistência. Gestão social.

\section{Precariousness and interdisciplinarity in the professional activity of the Social Worker in the public} sphere

Abstract: This article presents research with social workers in the position of managers, operating in the areas of social assistance, health, and in the judiciary of the Federal District of Brazil, emphasizing the context of social protection policies. The objective was to analyze the social perceptions of these managers about the precariousness and interdisciplinarity of the work of social workers in their interaction with psychologists. The methodology is qualitative through semi-structured interviews. The results point to the precariousness of Social Work in the neoliberal context, with consequences of overload and stress in the professionals' daily lives.

Keywords: Precariousness of work. Social Work in health. Social Work in the social-legal field. Social Work and assistance. Social management.

Recebido em 11.09.2018. Aprovado em 20.11.2018. Revisado em 29.04.2019.

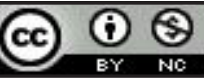

(C) O(s) Autor(es). 2019 Acesso Aberto Esta obra está licenciada sob os termos da Licença Creative Commons Atribuição-NãoComercial 4.0 Internacional (https://creativecommons.org/licenses/by-nc/4.0/deed.pt_BR), que permite copiar, distribuir e reproduzir em qualquer meio, bem como adaptar, transformar e criar a partir deste material, desde que para fins não comerciais e que você forneça o devido crédito aos autores e a fonte, insira um link para a Licença Creative Commons e indique se mudanças foram feitas. 


\section{Introdução}

O trabalho dos gestores no sistema público, que vem sendo modificado no contexto do neoliberalismo, está contraditoriamente articulado a uma tripla dimensão: precarização dos direitos sociais pela redução do Estado, precarização das condições de trabalho e a precarização da situação da população num contexto de exploração e de desigualdade social. A precarização se define como um processo de degradação das conquistas sociais e dos direitos sociais do estado de proteção social, como das conquistas trabalhistas e do direito ao trabalho. Tais conquistas são resultado de uma resposta às mobilizações sociais das classes trabalhadoras na dinâmica das crises capitalistas, visando estimular o consumo e fortalecer a demanda, na visão keynesiana, para conter a baixa tendencial da taxa de lucro (FALEIROS, 2008).

O capital tem como base de sustentação a articulação contraditória do pressuposto de que a exploração assegure o mínimo de subsistência para a mercadoria força de trabalho se reproduzir e, ao mesmo tempo, produzir a riqueza apropriada pelos donos dos meios de produção (MARX, 2011). O salário é que assegura a sobrevivência da força de trabalho. Esta, no entanto, precisa ser treinada e dirigida para render o máximo de produtividade para o patrão, configurando uma separação entre planejamento e execução, na obediência à hierarquia (FAYOL, 1990; TAYLOR, 1990).

A gestão do trabalho foi se consolidando com um corpo de funcionários que controla tanto seu processo como seu resultado. Instrumentos administrativos e técnicos de produção e de gestão da relação trabalhista seguem as exigências da competitividade e da lucratividade, atualmente globalizadas (ALVES, 2013). A tecnologia da informação vem possibilitar maior informatização dos processos produtivos, fazendo com que haja uma lógica geral do sistema que aumenta a produtividade ou mais-valia relativa, incorporando mais polivalência do trabalhador e exigência de capacitação (LOJKINE, 1995).

A gestão tem a função de articular a lógica do sistema com as relações de produção e relações entre trabalhadores. $\mathrm{O}$ contexto da gestão implica uma relação com o poder político, tanto em âmbito municipal, estadual, distrital como federal, ou dependendo da área específica que define normas próprias como o judiciário, a saúde e a assistência social, áreas que são objetos desta pesquisa. A gestão também se define por um território específico estabelecido na divisão política do País e na organização territorial das administrações, sendo que o planejamento das atividades depende da organização política e territorial, com maior ou menor presença de participação da sociedade, como conselhos, associações, fóruns e movimentos sociais.

Na perspectiva da Constituição de 1988 (BRASIL, [2018]), configura-se a proteção social, definida por direitos a serem efetivados e a participação do cidadão, sendo referência para a atuação profissional, o que demarca uma regulação da exploração do capital. É nessa configuração de direitos e de provisão de serviços que se articula a gestão crítica das políticas sociais. Dessa forma, há conflito entre demanda, ou melhor, de necessidades e prestação de serviços no contexto político-institucional de uma sociedade desigual. Aos conflitos de poder público e condições do serviço combinam-se os conflitos entre os profissionais (EIDELWEIN, 2007; SENRA; GUZZO, 2012).

$\mathrm{Na}$ área das políticas sociais, as demandas/necessidades são expressas de forma diversificada, conforme sua emergência, num fluxo estabelecido em um contexto normativo de

Levar em conta o trabalhador no processo de trabalho e dar-se conta do demandante ou mesmo dar conta do trabalho é um processo complexo que articula 0 contexto geral com a particularidade e a singularidade das situações, necessitando-se permanentemente decifrar, estrutural e conjunturalmente, 0 contexto histórico dado. cada órgão. As demandas sociais estão estruturadas pela desigualdade no contexto da exploração capitalista, sendo complexas e múltiplas. A miséria, a doença e a fome não se resolvem no mercado, demandam o Estado. São ao mesmo tempo socioeconômicas, políticas e culturais, implicando efetivação de direitos e proteção social. A proteção social é a garantia da vida, da saúde, do benefício, assistencial ou previdenciário, da convivência, da educação, do acesso à justiça e da segurança. A exemplo, a violência da negligência tem a ver com a estrutura socioeconômica, política, cultural, ou seja, com as relações de classe, gênero, raça, tornando-se questão da renda familiar, do desemprego, do machismo, dos conflitos interpessoais. Os desafios da gestão são múltiplos (SENRA; GUZZO, 2012), os gestores e os assistentes sociais estão subme- 
tidos a constrangimentos diante das formulações das políticas sociais e dos processos de intensificação e precarização do trabalho nos espaços institucionais públicos e privados (RAICHELIS, 2013).

$\mathrm{Na}$ atual configuração neoliberal predomina a restrição de direitos, aliada à pressão para a redução de custos e demandas, inserindo-se sorrateiramente o clientelismo articulado ao neoliberalismo, em contradição com o próprio projeto ético-político da profissão de assistente social. Segundo Paula (2014), os desafios da consolidação do Sistema Único de Assistência Social (SUAS), como política pública desde 2005, apesar do aumento dos conselhos, são a globalização, a focalização, a política neoliberal e a reestruturação produtiva. Paula (2014) salienta ainda a desprofissionalização e a contraposição entre as propostas de participação e de consolidação de direitos com a função gerencial e o clientelismo. A materialização do trabalho do assistente social se transmuta em execução, como se fosse apenas operador de benefícios como, Bolsa Família, o Serviço de Proteção e Atendimento Integral à Família (Paifi) e o Programa de Erradicação do Trabalho Infantil (Peti). Como assinalam Brisola e Silva (2014), a precarização do trabalho do assistente social nos municípios se efetiva por vários tipos de contratação como, estatutário, Consolidação das Leis do Trabalho (CLT), temporário, comissionado, cooperado e mesmo sem vínculo. Com a sanção da Lei no 13.429/2017 (BRASIL, [2017]), a terceirização passa a ser a forma instituída de contratação para atividades-fim e meio, acentuando-se a precarização e precariedade do trabalho socioassistencial.

\section{Gestão social nas áreas sociojurídica, da assistência social e da saúde}

O universo da pesquisa abrangeu o sociojurídico, a assistência social e a saúde, visando não só considerar a diversidade das percepções e vivências como o trabalho conjunto entre assistente social e psicóloga(o).

O Serviço Social sociojurídico foi implementado em São Paulo em 1949 e os psicólogos foram inseridos no Tribunal de Justiça de São Paulo (TJSP) em 1981 (FÁVERO; MELÃO; JORGE, 2005). Na área da saúde as chamadas visitadoras sociais, já antes mesmo de serem implementadas as primeiras escolas de Serviço Social, eram encarregadas de vigilância e inquérito social (PINHEIRO, 1985). Quanto à Psicologia, Spink (2003, p. 30) assinala que, "embora intimamente relacionada com o conceito de saúde, como disciplina, chega tardiamente à área da saúde. Chega 'miúda', tateando, buscando definir seu campo de atuação". Lembra ainda que "a grande virada, no que diz respeito à inserção dos psicólogos nos serviços de saúde em São Paulo, ocorreu a partir de 1982, com a adoção de uma política explícita, por parte da Secretaria de Saúde, de desospitalização e de extensão dos serviços de saúde mental". (SPINK, 2003, p. 31). A área da assistência social é também apropriada pelo Serviço Social desde a década de 1930, mas nessa época focada no desajustamento da condição miséria e pauperismo para, segundo Pinheiro (1985, p. 17) "reconduzir o desajustado à vida normal", o que tem sido objeto de profundas críticas (FALEIROS, 2015).

A legislação do final do século XX e início do século XXI coloca assistentes sociais e psicólogos no mesmo barco do trabalho conjunto nas áreas sociais, sendo que há obrigatoriedade de contratação de assistentes sociais, conforme dispositivos legais nas áreas de saúde, assistência e sociojurídica, ampliada para área de educação.

$\mathrm{Na}$ perspectiva da legislação, o que se busca não é somente a multidisciplinaridade, mas a interdisciplinaridade, concebida como ruptura de uma especialização fragmentada para a construção de um compartilhamento do conhecimento e atuação conjunta (MINAYO, 2010). Essa experiência de trabalho conjunto obrigatório, como foi assinalado, é recente no Brasil, existindo pouca formação para a interdisciplinaridade nas universidades, que fragmentam o acesso a determinado conhecimento (EIDELWEIN, 2007). Nesse contexto de trabalho conjunto determinado pela lei ou pelas normas, é que se coloca a pesquisa de percepção da gestão por parte de assistentes sociais gestoras. No contexto desta pesquisa busca-se compreender as percepções que têm as gestoras assistentes sociais sobre o trabalho profissional nas respectivas áreas de atuação.

\section{Método}

Foram entrevistadas nove assistentes sociais gestoras, três de cada área, depois de aprovação pelo Conselho Nacional de Desenvolvimento Científico e Tecnológico (CNPq) (Processo 477472/2011-7) e pelo Comitê de Ética (Parecer no 60646 de 25/07/2012 do Comitê de Ética da Universidade Católica de Brasília). A pesquisa é de caráter qualitativo e descritivo-interpretativo, tendo o foco de captar a percepção social (TRÓCCOLI, 2011) das profissionais. O contato com as nove gestoras foi realizado por meio de amostragem por conveniência, com adesão voluntária. O universo de pesquisa é demarcado por equipes caracterizadas como interdisciplinares (EIDELWEIN, 2007) e/ou multidisciplinares. A pesquisa foi divulgada verbalmente para psicólogos e assistentes sociais, reforçando-se que a participação era voluntária. A escolha desses três 
universos visou considerar a diversidade das percepções por grupo respectivo, considerando as relações da gestão com: a formação acadêmica; o contexto político e as posições políticas; com os profissionais das equipes; com o público atendido; com as normas instituídas; com as novas demandas de tecnologia da informação (TI) e conhecimento e a ética e gestão. A entrevista foi gravada e transcrita, depois analisada por temáticas, buscando-se o aprofundamento das percepções e a análise de conteúdo no contexto da precarização e do neoliberalismo, numa perspectiva crítica e dialética que relaciona história e contexto (ANDERY; SÉRIO, 2012).

Para sistematizar os resultados foi usado o software Alceste, organizando as falas por área de atuação, com posterior análise de conteúdo (BARDIN, 2008) articuladas ao marco teórico da precarização e normatização do trabalho das assistentes sociais e em sua relação com o trabalho psicológico. A discussão dos resultados considera os segmentos de fala das gestoras assistentes sociais nas três áreas objeto da pesquisa, levando em conta os depoimentos das gestoras da assistência social, da área jurídica e da área de saúde. Em primeiro lugar são discutidos os dados relativos à área da assistência social.

\section{Precarização e interdisciplinaridade na área da Assistência Social}

A proteção social como política pública na área da assistência social se consolidou com a promulgação das leis da Lei Orgânica de Assistência Social (LOAS) e do SUAS. As falas foram classificadas por tempo de atuação no SUAS. Ao se analisar as falas na área da assistência social podemos distinguir três temas: o trabalho conjunto com psicólogos; a precarização do trabalho e a dificuldade de atendimento das desigualdades. Essas temáticas se coadunam com as perspectivas teóricas assinaladas no contexto neoliberal em que se situa a política de assistência social, embora busque assegurar direitos na particularidade de um trabalho interdisciplinar. As contradições gerais se articulam com as contradições particulares desta atuação.

As gestoras assistentes sociais consideram que existe tanto colaboração como divergência com os psicólogos. A colaboração se expressa nas seguintes falas, considerando o momento do atendimento: "A psicóloga vem para até dar um norte para o assistente social de pontos que você não pode tocar em determinados momentos". (ENTREVISTADA 7, até dois anos de trabalho).

$\mathrm{Na}$ questão da saúde mental pode-se fazer uma parceria com a psicóloga, até mesmo fazendo visita juntas, conforme depoimento da Entrevistada 7. Outra gestora assinala que "no atendimento a gente esquece que esses profissionais psicólogos vieram para contribuir, para somar, para enriquecer o atendimento". (ENTREVISTADA 1).

Também se considera a importância de levar em conta o tipo de demanda, como o conflito familiar, já que "profissional que vem trabalhar no CRAS [Centro de Referência de Assistência Social] não vem feliz" e também muitos esperam que vão fazer clínica, mas "mesmo assim é necessário que a academia estimule essa parceria e a abertura para a intersetorialidade das práticas". (ENTREVISTADA 7). Outro depoimento assinala que "embora tenham os mesmos objetivos, a formação é totalmente diferente, necessitando-se qualificar profissionalmente o próprio serviço". (ENTREVISTADA 1).

O relacionamento conflituoso aparece quando, atendendo a uma família conjuntamente, a assistente social quer fazer de um jeito e a psicóloga de outro e isso acontece pela não compreensão exata da questão, "sendo complicada a articulação entre estudo de caso e acompanhamento da família e seria muito importante garantir uma dupla de atendimento". (ENTREVISTADA 7).

Os conflitos entre assistente social e psicólogos existem, pois em alguns momentos "pode ser guerra, e uma questão para o curso de psicologia é não ver a assistência social como uma coisa do assistente social" (ENTREVISTADA 7), assim, "as dificuldades de relacionamento também derivam da própria história dos serviços para lidar com as pessoas e também pela burocracia para implementar algumas coisas". (ENTREVISTADA 1).

Para resolver os conflitos propõe-se que exista flexibilidade no atendimento sem flexibilizar demais, pois "flexibilizar em excesso não faz a família crescer pois é preciso ter normas sociais e de cidadania". (ENTREVISTADA 7).

A precarização do trabalho é salientada na área pelas gestoras entrevistadas, por exemplo, a Entrevistada 1 considera que os serviços "estão precários com a falta de várias ferramentas com as quais precisariam trabalhar e com salários que são ruins para o profissional e isso reflete em conflitos". Acrescenta-se que

Há conflitos entre o que está na norma e a estrutura que existe para viabilizar esta norma, por exemplo, diante da grande demanda da população também se exige uma demanda por tecnologias, por coisas que facilitem e agilizem a realização do trabalho. (ENTREVISTADA 1). 
A mesma gestora considera que "é dificil lidar com a saúde e o adoecimento dos profissionais". Assinala ainda que o profissional tem "uma sensação de impotência ao tentar aplicar a normativa na realidade, ficando frustrado e doente, cansado e estressado". (ENTREVISTADA 1). Estresse, cansaço, frustração são expressões subjetivas da precarização e da taylorização do trabalho.

A Entrevistada 7 considera que "é muito importante que os órgãos públicos garantam o número de assistentes sociais para o trabalho", afirmando que

Nos CREAS [Centro de Referência Especializado de Assistência Social] existe uma dupla de atendimento, mas os CRAS estão com o número reduzido de servidores e aí acaba que nas unidades não existe psicóloga e garante o assistente social, e em outras garante o psicólogo e não garante o assistente social. (ENTREVISTADA7).

A precarização também se manifesta na falta de capacitação como expressa a Entrevistada 7: "outra coisa que eu acho também é que o gestor tem que ser atualizado, porque está lá, tem práticas antigas, eи me vejo muito assim".

Em síntese na área de assistência social ficou evidenciada a precarização do trabalho na falta de profissionais, falta de capacitação, falta de condições como tecnologias adequadas, na contradição entre demandas e recursos, com repercussões no estresse e na frustração, que por sua vez denotam sofrimento no trabalho.

\section{Precarização e interdisciplinaridade na área sociojurídica}

Existe uma especificidade do trabalho profissional de assistentes sociais e psicólogos na área jurídica onde predomina a hierarquia sob o comando do juiz ou do promotor. Salienta Derrida (2007) que na área jurídica as relações institucionais se configuram como uma forma em que o poder faz o direito. Em realidade, na esfera jurídica existe uma relação complexa entre a lei, o sujeito demandante, a prática da infração e as relações em presença, configurando litígios diversificados que exigem interpretações classificatórias, rituais e disputas que muitas vezes influenciam o processo de responsabilização e de punição ou absolvição. As relações conflituosas se manifestam na área psicossocial.

As gestoras assistentes sociais da área jurídica expressam essa hierarquia: "é uma instituição muito hierárquica, inclusive separada entre membros e servidores; os membros são vitalícios, típicos dessa instituição, $e$ os servidores são de assessoria a promotores e procuradores de justiça". (ENTREVISTADA 3).

A Entrevistada 3 assinala que não se trabalha sem a demanda dos promotores, mas que podem também trazer elementos para consideração dos promotores, conforme o depoimento abaixo:

[...] o trabalho conjunto de assistentes sociais e psicólogas tem dado uma cara diferenciada para assessoria que prestamos aos promotores, na verdade não trabalhamos sem a demanda das promotorias tanto quanto a gente faz uma pesquisa, quando a gente faz uma perícia, nessas duas linhas de trabalho assistentes sociais e psicólogas tem um diálogo constate para qualificar o trabalho, para ser um exercicio também de elucidação das profissões jurídicas, essencialmente jurídicas, do que significa falar desse espaço que seria social, desse espaço que seria psicológico, na verdade esse espaço que seria psicossocial dessa construção de subjetividade.

O fato de ser gestora abre também a possibilidade de se exercer uma correlação de forças, conforme Faleiros (2015), onde é necessária a construção de estratégias e táticas de ação:

[...] acho que o meu lugar de gestora dá um certo poder político pra negar algumas coisas, algumas perguntas que venham pra mim de uma entrevista forense eu digo que não faço e é respeitado, mas assim em alguns profissionais eles se pressionaram a fazer. Então pra gente atender uma criança numa entrevista é fundamental que a gente tenha uma compreensão antes da realidade dela, é um princípio ético senão é fazer uma mera entrevista, mas a gente tem que fazer uma mera entrevista. (ENTREVISTADA6).

Busca-se um trabalho compartilhado em função dos demandantes conforme salienta a Entrevistada 3, refletindo que é necessário construir uma equipe com perfis diferentes numa tentativa de um trabalho mais democrático: 
Seria uma relação mais simétrica possivvel, o cargo ele é temporário e ele na verdade significa atribuições, ele não significa mandar em pessoas pra fazer nada, seria muito mais a questão da atribuição e do trabalho diferenciado. A tentativa de relação simétrica de decisões compartilhadas, do compromisso compartilhado com as assistentes sociais e psicólogas. (ENTREVISTADA 3).

Nesse tipo de instituição, no entanto é preciso considerar as normas e os resultados na língua, no formato dominante da instituição:

[...] é uma instituição que ainda fala na língua dos números quanto mais processos você trabalhou, quanto mais documentos produziu, quanto mais certidão vocêfez, são os números que contam e esse é um grande problema de várias instituições tanto de políticas públicas, os ministérios, o executivo, também da execução desses serviços em que o que conta é quantos atendimentos você fez e não qual a natureza do seu trabalho e o que você pode fazer para que a gente melhore a nossa atuação, então essa é uma dificuldade de fazer com que essas normas valham. (ENTREVISTADA 3).

No entanto é necessário que se possa trabalhar mediações que implicam “[...] negociações cotidianas [...]”:

Não é porque as normas existem que elas necessariamente são seguidas à risca, elas dependem também de negociações cotidianas, por exemplo, o setor de estudos macrossociais ele existe, mas só conseguimos fazer que ele se consolidasse inclusive com uma pessoa específica só nele desde junho, antes ele existia, mas as atividades eram confusas, eram conjuntas com outros tipos de atividades embora ele já existisse na norma como fosse algo completamente diferente, as atribuições são diferentes de um setor de perícia e de um setor de pesquisas, por exemplo, mas as atividades iam acontecendo de forma concomitante. (ENTREVISTADA3).

Busca-se fazer um trabalho de forma mais interdisciplinar possível:

O diálogo porque nenhum projeto é construído por mim, sozinha, aqui dentro sempre tem diálogo, tanto quanto com os assistentes sociais como com as psicólogas do setor pra definirmos o que é importante pra gente dentro das nossas possibilidades, o que é importante tanto para categoria de assistentes sociais, pra categoria de psicólogas, então isso é também essencial nessa definição. Estamos tentando, dentro da Secretaria, fazer com que o trabalho seja o mais interdisciplinar possível, que esses diálogos sirvam para que a gente consiga sistematizar uma prática profissional que leve em consideração várias perspectivas. (ENTREVISTADA3).

No entanto existe a precarização do trabalho, principalmente com a sobrecarga e a falta de pessoal:

Ainda não temos muito definido qual é o nosso projeto como Secretaria dentro dessa instituição, as coisas estão sendo construídas aos poucos. Uma sugestão seria que se ampliasse o quadro pra que tivéssemos uma quantidade de profissionais equivalente e pudéssemos trabalhar muito mais em parceria do que numa assessoria, a gente precisa do seu auxílio, porque elas ficam muito sobrecarregadas porque acabam tendo que responder uma demanda que não é só da carga de trabalho delas, mas que a gente ainda precisa de auxílio e assessoria. Uma sugestão aumentar o quadro de psicólogas que é o mais urgente. (ENTREVISTADA3).

Quanto à precarização, ainda é necessária mais capacitação:

A busca de informação é muita nessa área da tecnologia, existe um serviço de treinamento no Tribunal. Acho que é muito investimento oferecer curso e de buscar que os gestores se capacitem nessa área, acho que ainda é pouco exigir só 30 horas a cada 2 anos. (ENTREVISTADA 6).

Embora a hierarquização predomine é necessário a compreensão de que o trabalho psicossocial é um espaço de conflito:

Acho que as situações quando chegam na justiça é que é o extremo da ausência de garantias, acho que é um espaço de exercício da cidadania e garantia de direitos, é a justiça que pode proporcionar isso. Acho que os usuários têm seus direitos vedados, eles procuram a justiça pra essa garantia, ao mesmo 
tempo a justiça é um espaço também de transformação da realidade que chega aqui, não é só no exercício da lei por si só, mas é uma reflexão do que o trouxe à justiça que faz ter esse espaço transformador e consciência do seu papel de sujeito. (ENTREVISTADA 6).

Em síntese, na área sociojurídica a pesquisa constata que as relações de poder, em especial a hierarquia, se articulam às questões do poder legalmente estabelecido e com a pressão para o cumprimento de tarefas, mas com a busca de assegurar a cidadania e a proteção social. Vive-se a contradição de se promover direitos num sistema judiciário que deve regular direitos. As gestoras convivem diuturnamente com a negação de direitos à população.

\title{
Precarização e interdisciplinaridade na área da saúde
}

$\mathrm{Na}$ área da saúde as gestoras entrevistadas também expressam as contradições entre as normas e a estrutura existente para o atendimento, a precarização das condições de infraestrutura e os conflitos e colaboração entre profissionais. A demanda é muito superior às condições oferecidas, mostrando a expressão de necessidades não atendidas pelas políticas públicas e pela rede de serviços, numa sociedade desigual. Os conflitos institucionais se manifestam na falta de recursos e de rede de atendimento, conforme a Entrevistada 2:

\begin{abstract}
Na instituição os maiores limites são extra institucionais porque quando não temos serviços substitutivos que consigam atender as demandas do hospital de saúde mental, não temos como dar vazão às demandas que temos aqui, os principais limites que temos aqui acontecem por conta da falta de serviços substitutivos da falta de rede, por exemplo, o pronto socorro hoje tem capacidade para 40 pacientes, hoje em dia temos 83 pacientes internados no pronto socorro, estamos funcionando acima do dobro que temos capacidade. Os maiores limites que temos seria a contratação de novos servidores para dar conta do número de demandas que temos, por exemplo, no quadro do serviço social precisaríamos pelo menos de dobrar o quadro para dar conta das demandas.
\end{abstract}

Este depoimento mostra também a precarização do trabalho não só pela falta de profissionais e de redes, mas também de organização, trazendo sobrecarga e estresse para os profissionais:

A formalização do Núcleo de Psicologia facilitaria a questão da relação do social e com todos os outros setores e áreas de atuação no hospital, teriam o seu papel mais legitimado, mais reconhecido dentro da unidade, isto seria fundamental para que a psicóloga entendesse a casa melhor. (ENTREVISTADA 2).

Lembra que os profissionais são comprometidos tanto com o atendimento como coma defesa dos direitos, mas o núcleo dirigente ou dominante das instituições não olha para a execução, trazendo um tipo de gestão burocrática distante para com os profissionais, diferente da gestão próxima realizada pela gestora assistente social:

Os profissionais são comprometidos, o que falta mesmo são questões de recursos físicos, as instalações são velhas, não temos material para realizar o nosso trabalho em grupo com eficiência a questão da informatização foi muito tardia, agora que estamos começando a usar o prontuário eletrônico, percebo que as questões na saúde mental principalmente são lentas e pra superar precisaria de um olhar diferenciado dos gestores centrais pra conseguir superar esses limites que temos aqui. (ENTREVISTADA 2).

No entanto, a parceria está em construção e a gestora busca, apesar das condições de uma separação, maior entrosamento do atendimento psicológico com o trabalho conjunto, o que depende da iniciativa e não de uma estrutura organizativa, e quando existe, consegue-se mais parceria:

Mas que a equipe esteja qualificada se ela não tem essa dinâmica de entrosamento mesmo, de parceria não conseguimos ter eficiência, a eficiência eu coloquei por último porque ela é o fim, quando conseguimos ter esse entrosamento essa articulação da equipe por fim conseguimos ter eficiência, às vezes a equipe está em primeiro, mas a falta de recursos humanos que é a limitação que eu coloquei em terceiro ela fragiliza a questão da eficiência acho que foi por aí que coloquei essa ordem. (ENTREVISTADA 2).

$\mathrm{Na}$ área da saúde as demandas são muito mais acima da capacidade existente de atendimento, o que precariza o trabalho, além da fragmentação organizativa, com necessidade da tomada de iniciativas pessoais, 
fazendo com que a própria gestora faça atendimento diante das demandas e da atenção aos direitos sociais. A falta de estrutura de outros setores coloca que muitas demandas geralmente acabam chegando ao Serviço Social, sobrecarregando os profissionais. A gestora assinala que:

\begin{abstract}
A minha profissão de gestora atualmente no hospital eu vejo prejudicada por conta do quadro, acabo tendo que assumir muitas funções e a questão da gestão mesmo, por exemplo, temos um projeto de fazer cursos, outros cursos de capacitação para os técnicos e, às vezes, não conseguimos dar todo aquele olhar pra questão de capacitação de cursos, enfim, porque não dá tempo, acabamos sendo atropeladas, tenho que atender as demandas, dar conta das reuniões de gestão, participar de eventos, de palestra, de reuniões com a gerência, com a direção e, além disso, dar conta de atender os usuários, dar conta de atender o programa vida em casa são 430 pacientes em todo o Distrito Federal. (ENTREVISTADA 2).
\end{abstract}

No contexto neoliberal as políticas de saúde vêm sofrendo restrições no sentido da privatização e do corte de verbas, no contexto da chamada política de austeridade que se torna meio para mercadorizar cada vez mais os serviços de saúde. A pesquisa mostra a defasagem entre demandas e condições de trabalho, embora programas novos sejam criados. A capacitação é deficiente e as demandas são muito diversificadas para gestão, dividida entre a burocracia, a resolução de conflitos e o trabalho cotidiano. As condições de precarização repercutem na saúde dos trabalhadores, o que acontece tanto em Portugal (LIMA, 2016) como no Brasil, acentuando o adoecimento dos assistentes sociais (VICENTE, 2015). A terceirização, considerada imprescindível num processo de gestão capitalista da mais-valia tem também profundas repercussões nas condições de saúde dos trabalhadores (LOURENÇO, 2015).

\title{
Considerações finais
}

Esta pesquisa salientou a contradição entre a formulação da política de proteção social e a realidade da desproteção, no contexto capitalista da desigualdade. Essas contradições expressam-se em uma multidimensionalidade de interações, destacando-se: a cooperação e o conflito interprofissional, mesmo na busca de interdisciplinaridade; a contradição e o conflito entre normas e exercício profissional de defesa de direitos, conforme o projeto ético-político dos Códigos de Ética profissionais; a contradição e o conflito entre demandas da população e as capacidades e dispositivos institucionais. A contradição fundamental, no entanto, é a da relação capital/trabalho, que estrutura a sociedade capitalista na produção da mais-valia. Para Marx (2011), o trabalho só tem valor de uso na medida em que é valor de troca, mas seu valor de uso tem incidência nesse valor de troca e pode ser utilizado diferentemente no processo de produção.

Assim, a modificação do trabalhador tem implicações para si e para o outro, bem como para o capital. As condições de exploração do trabalho estão na base da sua precarização, com o aumento das horas, da intensidade do trabalho, da demanda atendida, da redução de recursos. A condição de desgaste do trabalhador e seu adoecimento são decorrência dessa relação.

$\mathrm{O}$ adoecimento da assistente social no trabalho implica também o fato de inserir-se na defesa dos direitos dos demandantes na proteção social, superando tanto a moral humanista da caridade como a ética humanista presente na política desse encarregar do outro (KARSZ, 2004), bem como de só cuidar de providências objetivas (vales e benefícios) ou mesmo de encaminhamentos.

Levar em conta o trabalhador no processo de trabalho e dar-se conta do demandante ou mesmo dar conta do trabalho é um processo complexo que articula o contexto geral com a particularidade e a singularidade das situações, necessitando-se permanentemente decifrar, estrutural e conjunturalmente, o contexto histórico dado. No século XXI o contexto capitalista acentua o neoliberalismo, a redução da proteção social, a terceirização do trabalho, a redução de custos e de condições, com as repercussões no sofrimento e adoecimento dos trabalhadores e na negação de direitos e acesso da população aos serviços públicos.

\section{Referências}

ALVES, G. Dimensões da precarização do trabalho: ensaios de sociologia do trabalho. Bauru: Canal 6, 2013.

ANDERY, M. A. P. A.; SÉRIO, T. M. de A. P. A prática, a história e a construção do conhecimento: Karl Marx (1818-1883). In: ANDERY, M. A. P. A. et al. Para compreender a ciência: uma perspectiva histórica. 16. ed. Rio de Janeiro: Garamond; São Paulo: EDUC, 2012. p. 393-419.

BARDIN, L. Análise de conteúdo. Lisboa: 70, 2008. 
BRASIL. [Constituição (1988)]. Constituição da República Federativa do Brasil de 1988. Brasília, DF: Presidência da República, [2018]. Disponível em: http://www.planalto.gov.br/ccivil_03/Constituicao/Constituicao.htm. Acesso em: 29 abr. 2019.

BRASIL. Lei $n^{\circ} 13.429$, de 31 de março de 2017. Altera dispositivos da Lei ${ }^{\circ}$ 6.019, de 3 de janeiro de 1974, que dispõe sobre o trabalho temporário nas empresas urbanas e dá outras providências; e dispõe sobre as relações de trabalho na empresa de prestação de serviços a terceiros. Brasília, DF: Presidência da República, [2017]. Disponível em: http://www.planalto.gov.br/ccivil_03/_ato2015-2018/2017/ lei/L13429.htm. Acesso em: 23 maio 2017.

BRISOLA, E. M. A.; SILVA, A. L. da. O trabalho do Assistente Social no SUAS. In: BRISOLA, E. M. A.; SILVA, A. L. da (org.). $O$ trabalho do Assistente Social no SUAS: entre velhos dilemas e novos desafios. Taubaté: Cabral, 2014. p. 75-112.

DERRIDA, J. Força de lei: o fundamento místico da autoridade. São Paulo: WMF Martins Fontes, 2007.

EIDELWEIN, K. Psicologia social e Serviço Social: uma relação interdisciplinar na direção da produção de conhecimento. Textos \& Contextos, Porto Alegre, v. 6, n. 2, p. 298-313, jul./dez. 2007.

FALEIROS, V. P. A política social do estado capitalista. 11. ed. São Paulo: Cortez, 2008.

FALEIROS, V. P. Globalização, correlação de forças e Serviço Social. São Paulo: Cortez, 2015.

FÁVERO, E. T.; MELÃO, M. J. R.; JORGE, M. R. T. (org.). O Serviço Social e a psicologia no judiciário: construindo saberes, conquistando direitos. São Paulo: Cortez, 2005.

FAYOL, H. Administração industrial e geral. 10. ed. São Paulo: Atlas, 1990.

KARSZ, S. Pourquoi le travail social ? Définition, figures, clinique. Paris: Dunod, 2004.

LIMA, R. C. C. As políticas de saúde e de drogas em Portugal e no Brasil em período de austeridade econômica. In: MARTINS, A. et al. (org.) Serviço Social Portugal - Brasil: formação e exercício em tempo de crise. Campinas: Papel Social, 2016. p. 183-196.

LOJKINE, J. A revolução informacional. São Paulo: Cortez, 1995.

LOURENÇO, E. A. S. Terceirização: a derruição de direitos e a destruição da saúde dos trabalhadores. Serviço Social \& Sociedade, São Paulo, n. 123, p. 447-475, jul./set. 2015.

MARX, K. Grundrisse. São Paulo: Boitempo; Rio de Janeiro: Ed. UFRJ, 2011.

MINAYO, M. C. S. Disciplinaridade, interdisciplinaridade e complexidade. Emancipação, Ponta Grossa, v. 10, n. 2, p. 435-442, jul./ dez. 2010. Disponível em: http://www.revistas2.uepg.br/index.php/emancipacao/article/view/1937. Acesso em: 20 jan. 2016.

PAULA, R. F. S. A conjuntura de desafios para a gestão do trabalho no SUAS: entre a emancipação e a barbárie. In: BRISOLA, E. M. A.; SILVA, A. L. da (org.). O trabalho do Assistente Social no SUAS: entre velhos dilemas e novos desafios. Taubaté: Cabral, 2014. p. 45-74. PINHEIRO, M. E. Serviço Social: infância e juventude desvalidas: aplicações, formas, técnica, legislação. 2. ed. São Paulo: Cortez; Rio de Janeiro: Centro de Produção da UERJ, 1985.

RAICHELIS, R. Proteção social e trabalho do Assistente Social: tendências e disputas na conjuntura de crise mundial. Serviço Social \& Sociedade, São Paulo, n. 116, p. 609-635, out./dez. 2013.

SENRA, C. M. G.; GUZZO, R. S. L. Assistência social e psicologia: sobre as tensões e conflitos do psicólogo no cotidiano do serviço público. Psicologia \& Sociedade, Belo Horizonte, v. 24, n. 2, 293-299, maio/ago. 2012.

SPINK, M. J. P. Psicologia social e saúde: práticas, saberes e sentidos. Petrópolis: Vozes, 2003.

TAYLOR, F. W. Principios de administração científica. 8. ed. São Paulo: Atlas, 1990.

TRÓCCOLI, B. T. Cognição social. In: TORRES, C. T.; NEIVA, E. R. Psicologia social: temas e vertentes. Porto Alegre: Artmed, 2011. p. 79-99.

VICENTE, D. Desgaste mental de Assistentes Sociais: um estudo na área da habitação. Serviço Social \& Sociedade, São Paulo, n. 123, p. 562-581, jul./set. 2015 .

\section{Vicente de Paula Faleiros}

vicentefaleiros@terra.com.br

Doutorado em Sociologia pela Université de Montreal (UdeM)

Professor emérito do Departamento de Serviço Social da Universidade de Brasília (UnB)

\section{UnB}

Departamento de Serviço Social

Campus Universitário Darcy Ribeiro - ICC Norte

Brasília - Distrito Federal - Brasil

CEP: 70.910-900

\section{Helga Cristina Hedler}

helgachededler@gmail.com

Doutorado em Psicologia Social, do Trabalho e das Organizações pela Universidade de Brasília (UnB) 
Professora e pesquisadora do Mestrado em Governança, Tecnologia e Inovação da Universidade Católica de Brasília (UCB)

\section{UCB}

Campus Asa Norte

SGAN 916, Módulo B, W5 Norte - Asa Norte

Brasília - Distrito Federal - Brasil

CEP: 70.790-16

\section{Adelina Almeida Moreira de Araújo}

profninamoreira@gmail.com

Mestrado em Serviço Social pela Universidade Federal da Paraíba (UFBP)

Doutoranda em Psicologia na Universidade Católica de Brasília (UCB)

\section{UCB}

Campus Taguatinga

QS 07, Lote 01, EPCT - Taguatinga

Brasília - Distrito Federal - Brasil

CEP: 71.966-700

\section{Agradecimentos}

Às pesquisadoras de campo e Assistentes Sociais entrevistadas e ao CNPq pelo apoio à pesquisa.

\section{Agência financiadora}

Conselho Nacional de Desenvolvimento Científico e Tecnológico (CNPq). Processo: 477472/2011-7.

Período de Execução: fevereiro de 2013 a dezembro 2015.

\section{Contribuições dos autores}

Projeto de pesquisa: Vicente de Paula Faleiros e Helga C. Hedler. Compilação dos dados: Vicente de Paula Faleiros e Helga C. Hedler.

Redação: Vicente de Paula Faleiros e Helga C. Hedler.

Revisão: Adelina Almeida Moreira de Araújo.

\begin{abstract}
Aprovação por Comitê de Ética e consentimento para participação

Projeto aprovado pelo CNPq (Processo 477472/2011-7) e pelo Comitê de Ética, conforme Parecer no 60646 de 25/07/2012 do Comitê de Ética da Universidade Católica de Brasília. O consentimento foi feito por meio de um Termo de Consentimento Livre e Esclarecido assinado pelas participantes.
\end{abstract}

\section{Consentimento para publicação}

Não se aplica (pois os dados pessoais dos participantes não são divulgados).

\section{Conflito de interesses}

Não há conflito de interesses. 